\title{
Civil Aircraft Emissions Study and Pollutant Forecasting at a Brazilian Airport
}

\author{
Daniel Alberto Pamplona \\ Air Transportation Department \\ Aeronautics Institute of Technology \\ Sao Jose dos Campos, Brazil \\ pamplonadefesa@gmail.com
}

\author{
Claudio Jorge Pinto Alves \\ Air Transportation Department \\ Aeronautics Institute of Technology \\ Sao Jose dos Campos, Brazil \\ claudioj@ita.br
}

\begin{abstract}
In recent decades, the emissions of air transport industry pollutants and their impact on human health attract increased focus. The continued growth of air traffic and public awareness has transformed this field into one of the most important topics of commercial aviation. In the next 20 years, the estimated global demand for air transport will grow by an average of $5 \%$. One of the direct consequences would be the increase in emissions, affecting significantly the communities around airports. The aim of this paper is to present an econometric model forecast of pollutant emissions generated by domestic flights in Salvador Airport. This model includes a derivative study of demand until the year 2020, considering the number of flights and emissions generated in the takeoff and landing cycles. Results present a predictive model for the number of pollutant emissions.
\end{abstract}

\section{Keywords-pollution; air transportation; forecast}

\section{INTRODUCTION}

In recent years, the environmental effects of aviation, the impact of aircraft engines on the emission of pollutants and the consequences on health and quality of life of the residents, have become major discussion points. The energy consumption of the primary world increased by $2.2 \%$ in 2017 [1]. Moreover, fossil fuels are the most dominant energy source by a rate of $85 \%$ [2]. The burning of fossil fuels emits pollutants such as nitrogen oxide $\left(\mathrm{NO}_{\mathrm{x}}\right)$, carbon monoxide $(\mathrm{CO})$, carbon dioxide $\left(\mathrm{CO}_{2}\right)$, sulphur dioxide $\left(\mathrm{SO}_{2}\right)$, and other harmful gases [3] Emissions from diesel fuels contribute to the occurrence of many respiratory, cardiovascular and cancer diseases. Besides air, water and soil pollution, these emissions cause visibility reduction and contribute to the global climate change [4]. One liter of combusted diesel fuel produces $2.9 \mathrm{Kg}$ of greenhouse gases, while one liter of combusted petrol produces $2.7 \mathrm{Kg}$ [5]. According to [6], mobile sources, such as various fuel type engines, directly emit $\mathrm{CO}_{2}$, methane $\left(\mathrm{CH}_{4}\right)$, nitrogen oxide $\left(\mathrm{N}_{2} \mathrm{O}\right)$, CO, non-methane volatile organic compounds (NMVOCs), $\mathrm{SO}_{2}$, Particulate Matter (PM), and $\mathrm{NO}_{\mathrm{x}}$ that cause or contribute to air pollution. The aim of this paper is to conduct a prediction study about the emission of pollutants at Salvador airport. This airport has the largest passenger and takeoff traffic in the Northeast region of Brazil. At first, the projected demand for the airport was used [7]. Consequently, a derived study for the emission of pollutants until 2020 was conducted, using data from the Intergovernmental Panel's on Climate Change (IPCC). The academic gain is achieved through the prediction of passenger's demand and the estimation of the emission of pollutants by regular flights. Unlike other studies, this emission forecast is not limited to a single model of aircraft, but studies various aircraft types.

\section{LITERATURE REVIEW}

Civil aviation as a cause of air pollution has attracted an increasing importance over the years, since the overall air traffic, conforming to former evaluations, is predicted to expand in the present and the upcoming decades [8]. Field and data investigations have showed an interrelationship between pollutant concentration and aircraft traffic at airports in the US and Europe [9]. In [10], the environmental impact of civil aviation was analyzed, given the high fuel consumption and the increase of the $\mathrm{CO}_{2}$ emissions. In [11], the importance of studying the impact on airport neighborhoods in a wide range of areas was pointed out, including the case of air pollution. The local impact of Zurich's airport traffic was studied in [12], examining additionally the variation of pollutant emissions. The ultrafine Particle Number Concentrations (PCNs) emitted at high rates by jet aircrafts at Logan International Airport (Boston, MA, USA) were examined in [13]. Results showed that PNCs were positively correlated with flight activity after considering weather conditions, time of day, week and traffic volume. The global impact of aircraft emissions near the Los Angeles International Airport (LAX) was assessed in [14], comparing the airport's with the vehicular emissions on roads. Particle accumulation was, on average, $4.1 \pm 1.2$ times higher at LAX's neighborhood than the considered freeways. Results revealed that LAX airport was a main source of pollution within its area of impact, compared to freeway emissions.

Health damage functions varied across airports for each precursor-pollutant relationship modeled in [15]. The variable patterns among health damage functions led to variable contributions of emitted pollutants to total health impacts across individual airports. Two measurement campaigns of total PNC, near a medium-size airport in central Italy (Ciampino airport), were implemented in [16], implementing statistical regression models relating PNC data to the presence of aircraft activities. In [17], the air quality and climate benefits of holding aircrafts at their gates for up to 25 minutes to reduce 
congestion minimizing fuel burn and emissions from taxi operations by $35-38 \%$, relative to no gate holds, was estimated. The future growth of aviation, the resulting fuel demand and the deployment of biofuels in the aviation sector in Europe was studied in [18], projecting data for aviation growth and fuel demand on a year-by-year basis up to 2030. Outdoor and indoor PNCs from 16 residences located in two study areas in the greater Boston metropolitan area were investigated in [19]. Results indicated that aviation-related outdoor PNC infiltrate indoors and resulted in significantly higher indoor PNC, providing evidence for the impact of aviation-related emissions on residential exposures.

Emissions from the engines are approximately $70 \% \mathrm{CO}_{2}$, slightly less than $30 \% \mathrm{H}_{2} \mathrm{O}$ and slightly less than $1 \%$ for $\mathrm{NO}_{\mathrm{x}}$, $\mathrm{CO}, \mathrm{SO}_{\mathrm{x}}$ and NMVOC. Modern engines emit low levels of $\mathrm{N}_{2} \mathrm{O} . \mathrm{CH}_{4}$ emissions can occur when the aircraft is idle, while modern aircrafts emit low levels of this gas. Aircraft operations are divided into Landing/Take-Off (LTO) cycle and cruise flight for the calculation of pollutants emissions [20]. Air pollutants, may have detrimental effects and environmental impacts and PM is one of the air pollutants affecting, by severe ways, public health. An increment in respiratory diseases is usually linked to PM pollution, mainly due to PM10 and PM2.5 air pollution [21]. $\mathrm{CO}_{2}$, a non-combusted gas released when fuels with carbon composition are combusted, is a substantial criterion of an engine's exhaust emissions. $\mathrm{CO}$ emissions are colorless, odor free and toxic. PM air pollution is an air-suspended combination of solid and liquid particles depending upon size, shape, surface area, number, chemical arrangement, solubility, and origin [22]. CO is responsible for cardiovascular diseases, especially in persons with heart problems. $\mathrm{NO}_{\mathrm{x}}$ cause lung irritation and lower resistance to respiratory infections. NMVOCs are responsible for eye and respiratory irritations, headaches, dizziness, visual disorders, and memory impairment [6]. IPCC data were used to determine $\mathrm{CO}_{2}, \mathrm{CH}_{4}, \mathrm{~N}_{2} \mathrm{O}, \mathrm{NO}_{\mathrm{x}}, \mathrm{CO}, \mathrm{NMVOCs}$ and $\mathrm{SO}_{2}$ emissions. When on ground and during the LTO cycle, an aircraft produces approximately $10 \%$ of its emissions, except hydrocarbons and $\mathrm{CO}$. The LTO cycle includes emissions during takeoff and landing below 3000 feet height [23].

This study uses a prediction of passenger demand model to estimate future environmental impacts, in relation to the emission of pollutants by regular flights in an airport, taking into account the variety of aircraft types.

\section{ESTIMATION MODEL AND RESULTS}

The projected demand for the Salvador airport, as studied in [7], was used to assess the impact of the economic growth in the number of domestic passengers. It was estimated that an annual economic growth of $1 \%$ would increase the number of domestic passengers by $0.744 \%$. Initially, the impact of $1,2,3$, and $4 \%$ of annual economic growth and the direct increase in the number of passengers was simulated. The results are shown in Figure 1. The expansion of passengers would lead the airlines to increase the number of flights, increasing the emissions of pollutants. A conservative annual economic growth of $1 \%$ was chosen and the flight schedule of July 2015 was used for the prediction of the total number of commercial aircrafts operating annually. Table I shows the percentage of aircraft types operating per week. An average aircraft passenger occupancy rate of $80 \%$ was used for total passenger estimation. Figure 2 shows the passengers' forecast from 2014 to 2020. Figure 3 shows the total number of aircrafts, per model, in the period from 2014 up to 2020.

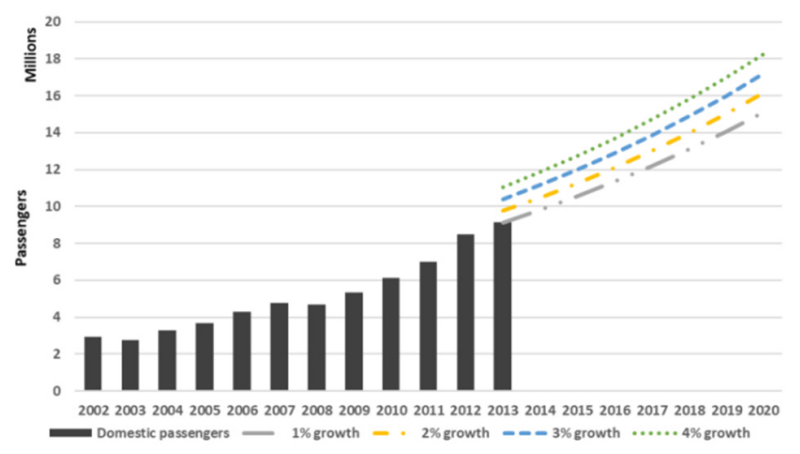

Fig. 1. Time series of the predicted number of passengers

TABLE I. PERCENTAGE OF AIRCRAFT TYPE PER WEEK

\begin{tabular}{|c|c|}
\hline Aircraft model & Participation (\%) \\
\hline A318 & 4 \\
\hline A319 & 3 \\
\hline A320 & 31 \\
\hline AT72 & 6 \\
\hline E190 & 12 \\
\hline B737-700 & 4 \\
\hline B737-800 & 36 \\
\hline Total & 100 \\
\hline
\end{tabular}

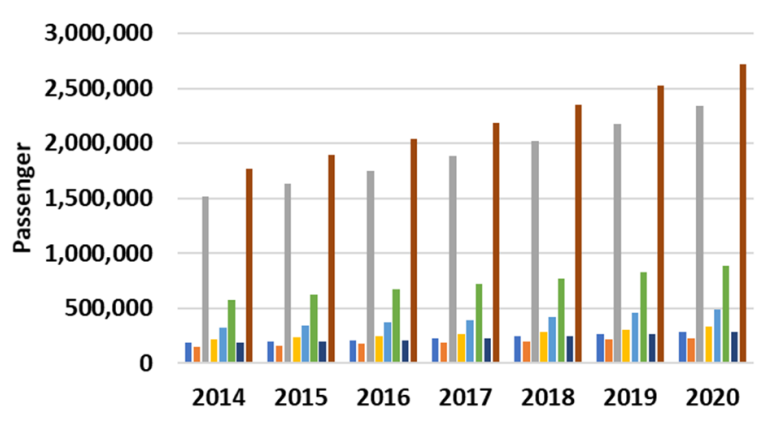

$\llbracket A 318 \backsim A 319 \backsim A 320 \backsim A 321 \backsim A T 72 \backsim E 190 \backsim B 737 \approx B 738$

Fig. 2. Passenger's forecast by aircraft type from 2014 to 2020

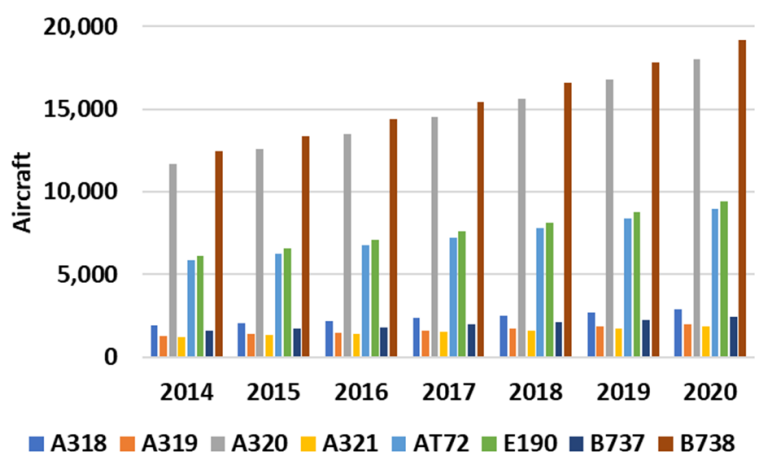

Fig. 3. Time series of the predicted number of aircrafts by type 
Figure 4 shows the total emission of pollutants estimated per year, where rows have their values represented on the left axis and columns on the right axis.

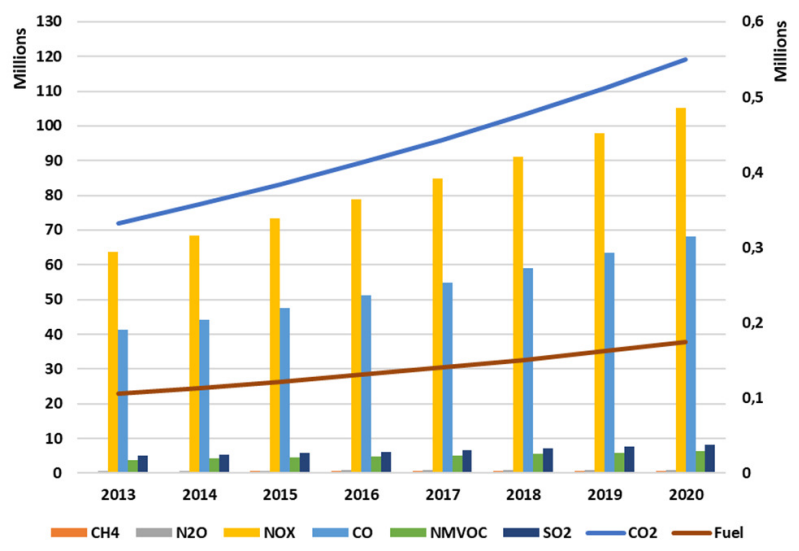

Fig. 4. Total emissions of pollutants estimated in Kg per year

Results show that the increase in air transportation demand will lead to an increase in the emission of pollutants. In the present study, a constant growth of demand of $0.744 \%$ per year would lead to a $65 \%$ increase in the emission of pollutants on 2020. The increase of gas emissions could lead to an increase to heart and respiratory diseases, among others, in the airport's surroundings. This notes the concern that should be taken with aviation and its effects on health.

\section{CONCLUSION}

In recent years, researchers have become more interested in the environmental effects of aviation. The aim of this article was to study and predict the emission of pollutants at Brazil's Salvador Airport. The study showed that increasing demand would increase the emission of pollutants, affecting the areas and the population living around the airport. The main problem of this method is that LTO data are only available for scheduled flights. General aviation flights, helicopters, instructional or leisure flights are not included in this methodology. In most countries, the emission levels of these flights would be insignificant, but may be significant, depending on country and region. In this study, these flights were considered insignificant.

Civil aviation is predicted to expand in the present and the upcoming decades. Academic studies have showed an interrelationship between pollutant concentration and aircraft traffic at airports, highlighting the importance of studying the impacts in airport neighborhoods in a wide range of areas, including air pollution. Studies should focus on airport base, since there is variability on aircraft fleet and traffic. Companies that have market dominance are those that emit more pollutants, bringing consequences to people living close to airports. Moreover, ways to compensate the community should be thought out. Future studies should focus on this aspect, seeking to investigate in the increase of flight frequency and hospital admissions. These findings point out the need for more environmental studies examining aircraft emissions in populated areas close to airports.

\section{REFERENCES}

[1] S. Saridemir, U. Agbulut, "Combustion, performance, vibration and noise characteristics of cottonseed methyl ester-diesel blends fuelled engine", Biofuels, Vol. 10, pp 1-10, 2019

[2] U. Agbulut, S. Saridemir, S. Albayrak, "Experimental investigation of combustion, performance and emission characteristics of a diesel engine fuelled with diesel-biodiesel-alcohol blends", Journal of the Brazilian Society of Mechanical Sciences and Engineering, Vol. 41, pp. 389, 2019

[3] U. Agbulut, “Turkey's electricity generation problem and nuclear energy policy", Energy Sources, Part A: Recovery, Utilization, and Environmental Effects, Vol. 41, No. 18, pp. 2281-2298, 2019

[4] U. Agbulut, S. Saridemir, "A general view to converting fossil fuels to cleaner energy source by adding nanoparticles", International Journal of Ambient Energy, Vol. 40, pp. 1-6, 2019

[5] U. Agbulut, H. Bakir, "The investigation on economic and ecological impacts of tendency to electric vehicles instead of internal combustion engines", Duzce Universitesi Bilim ve Teknoloji Dergisi, Vol. 7, No. 1, pp. 25-36, 2019

[6] Intergovernmental Panel on Climate Change, "2006 IPCC guidelines for national greenhouse gas inventories", Meeting Report: Industrial Processes and Product Use, Washington DC, USA, July 27-29, 2004

[7] D. A. Pamplona, A. V. M. de Oliveira, "Air delay costs and its impacts: airport demand study and simulation scenarios of economic welfare", Ciencia \& Engenharia, Vol. 23, No. 1, pp. 73-82, 2014 (in Portuguese)

[8] F. Vichi, M. Frattoni, A. Imperiali, C. Balducci, A. Cecinato, M. Perilli, P. Romagnoli, "Civil aviation impacts on local air quality: a survey inside two international airports in central Italy", Atmospheric environment, Vol. 142, pp. 393-405, 2016

[9] S. H. L. Yim, G. L. Lee, I. H. Lee, F. Allroggen, A. Ashok, F. Caiazzo, S. D. Eastham, R. Malina, S. R. H. Barret, "Global, regional and local health impacts of civil aviation emissions", Environmental Research Letters, Vol. 10, No. 3, Article ID 034001, 2015

[10] M. Grote, I. Williams, J. Preston, "Direct carbon dioxide emissions from civil aircraft", Atmospheric Environment, No. 95, pp. 214-224, 2014

[11] M. Masiol, R. M. Harris, “Aircraft engine exhaust emissions and other airport-related contributions to ambient air pollution: a review", Atmospheric Environment, Vol. 95, pp. 409-455, 2014

[12] G. Schurmann, K. Schafer, C. Jahn, H. Hoffmann, M. Bauerfeind, E. Fleuti, B. Rappengluck, "The impact of NOx, CO and VOC emissions on the air quality of Zurich airport", Atmospheric Environment, Vol. 41, No. 1, pp. 103-118, 2007

[13] N. Hudda, M. C. Simon, W. Zamore, D. Brugge, J. L. Durant, “Aviation emissions impact ambient ultrafine particle concentrations in the greater Boston area", Environmental Science \& Technology, Vol. 50, No. 16, 2016

[14] F. Shirmohammadi, M. H. Sowlat, S. Hasheminassab, A. Saffari, G. Ban-Weiss, C. Sioutas, "Emission rates of particle number, mass and black carbon by the Los Angeles International Airport (LAX) and its impact on air quality in Los Angeles", Atmospheric Environment, Vol. 151, pp. 82-93, 2017

[15] S. L. Penn, S. T. Boone, B. C. Harvey, W. Heiger-Bernays, Y. Tripodis, S. Arunachalam, J. I. Levy, "Modeling variability in air pollution-related health damages from individual airport emissions", Environmental Research, Vol. 156, pp. 791-800, 2017

[16] M. Stafoggia, G. Cattani, F. Forastiere, A. D. M. Di Bucchianico, A. Gaeta, C. Ancona, "Particle number concentrations near the RomeCiampino city airport”, Atmospheric Environment, Vol. 147, pp. 264273, 2016

[17] A. Ashok, H. Balakrishnan, S. R. H. Barrett, "Reducing the air quality and $\mathrm{CO}_{2}$ climate impacts of taxi and takeoff operations at airports", Transportation Research Part D: Transport and Environment, Vol. 54, pp. 287-303, 2017

[18] M. Kousoulidou, L. Lonza, "Biofuels in aviation: Fuel demand and $\mathrm{CO}_{2}$ emissions evolution in Europe toward 2030", Transportation Research Part D: Transport and Environment, Vol. 46, pp. 166-181, 2016

[19] N. Hudda, M. C. Simon, W. Zamore, J. L. Durant, "Aviation-related impacts on ultrafine particle number concentrations outside and inside 
residences near an airport”, Environmental Science \& Technology, Vol. 52, No. 4, pp. 1765-1772, 2018

[20] K. Rypdal, W. Winiwarter, "Uncertainties in greenhouse gas emission inventories: evaluation, comparability and implications", Environmental Science \& Policy, Vol. 4, No. 2-3, pp. 107-116, 2001

[21] A. A. Siyal, S. R. Samo, Z. A. Siyal, K. C. Mukwana, S. A. Jiskani, A. Mengal, "Assessment of air pollution by PM10 and PM2.5 in Nawabshah City, Sindh, Pakistan", Engineering, Technology \& Applied Science Research, Vol. 9, No. 1, pp. 3757-3761, 2019

[22] Q. B. Jamali, M. T. Bhatti, Q. A. Qazi, B. H. Kaurejo, I. A. Qazi, S. H. Solangi, A. S. Jamali. "Analysis of $\mathrm{CO} 2, \mathrm{CO}, \mathrm{NO}, \mathrm{NO} 2$, and $\mathrm{PM}$ particulates of a diesel engine exhaust", Engineering, Technology \& Applied Science Research, Vol. 9, No. 6, pp. 4912-4916, 2019

[23] International Civil Aviation Organization, "Local Air Quality", available at: https://www.icao.int/environmental-protection/Pages/local-air-quality .aspx, 2015 